\title{
METHOD OF EVALUATION OF THE MINIMAL SAMPLE SIZE FOR ACOUSTICAL SIGNAL THERAPY MONITORED VIA ELECTROENCEPHALOGRAPHIC ACTIVITY OF HUMAN BRAIN \\ Dmytro Pareniuk ${ }^{I}$ \\ ${ }^{1}$ Department of Acoustic and Multimedia Electronic Systems, National Technical University of Ukraine "Igor Sikorsky Kyiv Polytechnic Institute", Kyiv, Ukraine pdv091943-ames@111.kpi.ua \\ ORCID: https://orcid.org/0000-0002-0734-3183
}

ARTICLE INFO

Article history:

Received date 23.03.2021

Accepted date 20.04.2021

Published date 30.04.2021

Section:

Technologies and equipment of clinical medicine

D O I

$10.21303 / 2313-8416.2021 .001736$

\section{KEYWORDS}

electroencephalogram

bioelectrical activity

minimal sample size

music therapy

\section{A B S T RACT}

The aim of the study. Improvement of the preparation to the acoustical signal therapy test or experiment of electroencephalographic activity of human brain and validation of the specified test results.

The problem to be solved. Estimation of the minimal possible sample size for maintaining needed research accuracy in the research field of the electroencephalographic activity of human brain via monitoring of the brainwave patterns during exposure to the musical signal. Main scientific results. New method for selection minimal passable sample size for brainwave pattern studies is presented. Example of application of method for one rhythm of the brainwaves (delta-rhythm) is shown. Perspective way of obtaining clinically valuable differences between test group results was acquired. Differences between mean values for groups of results of different types of music and stress factor exposure are presented.

The area of practical use of the research results. Research facilities dedicated to the study of electroencephalographic activity of human brain and medical facilities and institutions, dedicated to the treatment of pathologies of the central nervous system, brain damage, stress, and progressive post-stress action psychological state restoration.

An innovative technological product. Dedicated method for quick estimation of minimal passable sample size for brainwave pattern studies, which is recommended for usage in the studies of the implementation of music therapy.

The area of application of an innovative technological product. Electroencephalographic activity of human brain study via brainwave pattern research. Clinical practice of application of a music therapy.

(C) The Author(s) 2021. This is an open access article under the Creative Commons CC BY license

\section{Introduction}

The human brain is highly sophisticated organ that renders humans as the most intelligent known species. That organ contains approximately 86 billion neurons. These neurons continuously make connections with one another in the form of electrical signals. Neuronal firings generate different types of wave patterns, which emanate from differing brain regions. These include delta $(<4 \mathrm{~Hz})$, theta $(4-7 \mathrm{~Hz})$, alpha $(7-12 \mathrm{~Hz})$, beta $(12-30 \mathrm{~Hz})$ waveforms [1]. The rhythms of the electroencephalogram (EEG) are defined as regularly recurring waveforms of similar shape and duration so it is possible to define studied objects also as an as $\alpha-, \beta$-, $\theta$ - and $\delta$-rhythms [2].

The clinical electroencephalography correlates central nervous system (CNS) functions as well as dysfunctions and diseases with certain patterns of the electroencephalogram (EEG) on an empirical basis. Because of the said this method has been found valuable in clinical practice [2].

Recently, there is increasing evidence of the use of musical intervention in a clinical conditions, concerning singing, music listening, musical improvisation, and other musical activities. Given that music engages a variety of brain areas involved in emotion, motivation, cognition, and motor functions, musical interventions have been used to increase socialization and cognitive, emotional, and neuromotor functioning. Music listening was implemented as a musical treatment during series of experiments, performed for this study [3]. 
As another influencing factor, prolonged stress study was used. Mentioned usage took place because there was need to establish strict set of conditions, in which music therapy will work in its full capability.

\section{1. The object of the research}

A method for selection of the minimal passable sample size for research of the relative $\alpha$-, $\beta$-, $\theta$ - and $\delta$-rhythms levels change due to exposition to superposition of external factors (musical therapy and long-term growing study stress level), has been obtained. Said method presentation includes ways of estimation of clinically significant difference between group means for brainwave rhythms.

\section{2. Problem description}

The field of the research of electroencephalographic activity of human brain is new and is rapidly advancing $[4,5]$. But, modern ways of utilizing this method do not include in pre-experimental preparations estimation of the proper size of the samples. A lot of studies form samples out of available test subjects, without statistical analysis of used group size even in post-processing of results $[6,7]$.

There is objective reason for said situation - not always presented clinical situation allows choice in sample size - disease, brain damage or harsh stress influence are hard to predict. Furthermore, exact condition of even presented patients may wary in wide borders [7]. Considering all before mentioned facts it is important to know when presented research may need further clarification.

Presented modern studies in estimation of the sample size either are done in different science field, which puts forward its' own requirements [8, 9], or are too generalized [10].

Because of before mentioned facts it is important to have way, which is specifically designed for usage in EEG field to both quickly and clearly calculate the needed number of experiment participants and properly estimate values by which said number is calculated.

\section{3. Suggested solution to the problem}

This study presents new method of pre-experimental sample size estimation for the task of evaluation of relative level of brainwave rhythms during, before and after brainwave pattern studies for both influenced via usage of superposition of external factors (musical therapy and long-term growing study stress level) brain and not influenced one.

The aim of this study is to estimate possibility of the application of basic statistical formulae [11] in the setting of the minimum possible sample size for EEG testing of the influence of superposition of two neurologically active factors - music signal and stress factor with prolonged action for $\delta$-rhythms examination and establishing value of clinically significant difference between group's mean values, which shapes sample size.

\section{Materials and methods}

The task of the experiments, for which the method was created, is to test the influence of two parameters - a low-frequency musical signal, which influenced patients during test, and stress factor in form of the study process, influencing patients long before test start, on certain brain rhythms, in presented case $\delta$-rhythms. Observed experimental results were also to be verified via statistical means for clarification of their correctness because of their small sample size. That verification was the reason of the method creation.

\section{1. Experimental methodology}

To research the stimulation of the human CNS with low audio signals was used musical fragment of selected properties (Fig. 1). Frequency with $\mathrm{A}_{\max }$ for selected fragment was estimated as $80 \mathrm{~Hz}[12]$.

Five student volunteers participated in the observed part of the experiments set, their informed consent was obtained, research was conducted with the strict accordance with the Code of Ethics of the World Medical Association (Declaration of Helsinki). Experiments also were supervised by two 
doctors, not affiliated with basic research facility - neurologist and psychiatrist. Students who participated in tests, of whom 2 were men and 3-women aged 18-22 years. Selected respondents had no special musical education, were right-handed, at the time of the study were healthy, had no history of traumatic brain injury, severe hearing problems, and diseases of the central nervous system. A total of 14 experiments were conducted - 7 in male and female groups. Number of sessions per person: 4 sessions - 2 people ( 1 person, 1 woman); 1 session -3 people ( 2 people, 1 woman).

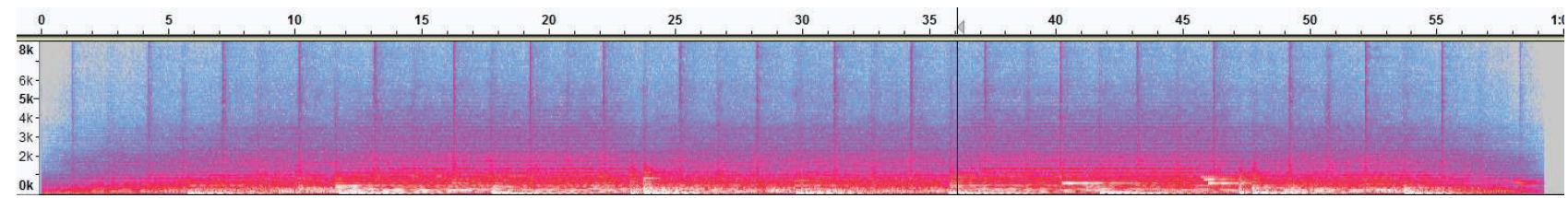

Fig. 1. Spectral properties of the used sound fragment (On Demon Wings by Bohren \& der Club of Gore)

The obtained results were divided into two groups (7 experiments each) - before the beginning of indirect exposure to time-stretched stress factors ( 3 experiments in women, 4 experiments in men) and after (4 experiments in women, 3 experiments in men).

The research of the effect of low-frequency audio signals exposure on the bioelectrical activity of the human brain was conducted in a certified silenced room on the base of the Department of Acoustic and Multimedia Electronic Systems National Technical University of Ukraine "Igor Sikorsky Kyiv Polytechnic Institute", electroencephalography experiments (EEG) was performed via computer electroencephalograph "BRAINTEST-16”, "DX-systems" Ukraine, Kharkiv).
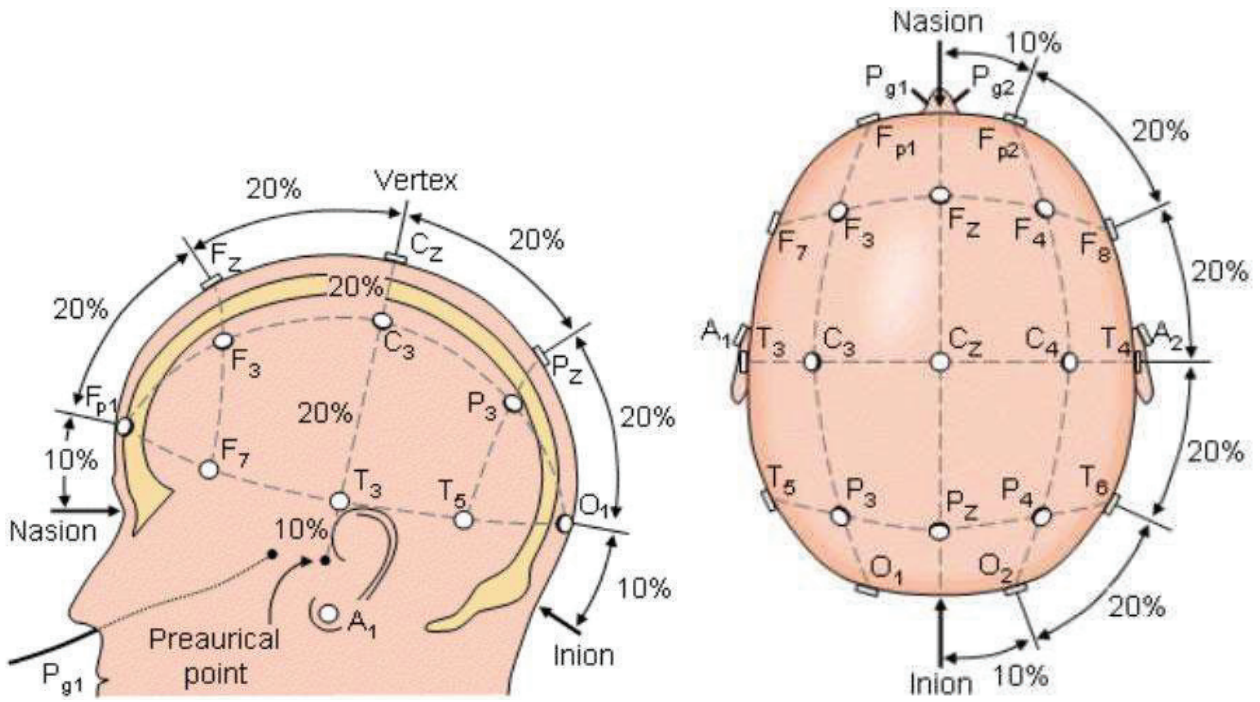

Fig. 2. International system 10-20, electrode placement scheme

Electrodes were located in 16 standard placements (Fr1, Fr2, F3, F4, F7, F8, C3, C4, P3, P4, O1, O2, T3, T4, T5, T6) - (Fig. 2), their correct placements were determined in accordance to international system "10-20" [13]. The potentials of the active electrodes were measured in relation to the zero reference electrodes placed on the earlobes. Raw data was recorded in 0.16$100 \mathrm{~Hz}$ bandwidth and later estimated via Fast Fourier Transformation (FFT) in bandwidth of 0.5 to $30 \mathrm{~Hz}$ (Fig. 3).

Experimental raw data has total length of 3 minutes of EEG recording - first minute the silence in musical signal is recorded, second minute is low-frequency musical signal exposure and the last one is also silence. The purpose of first minute's exposure of examinee to the silence is establishing background level for test, and third minute allows musical therapy's influence to set in. 


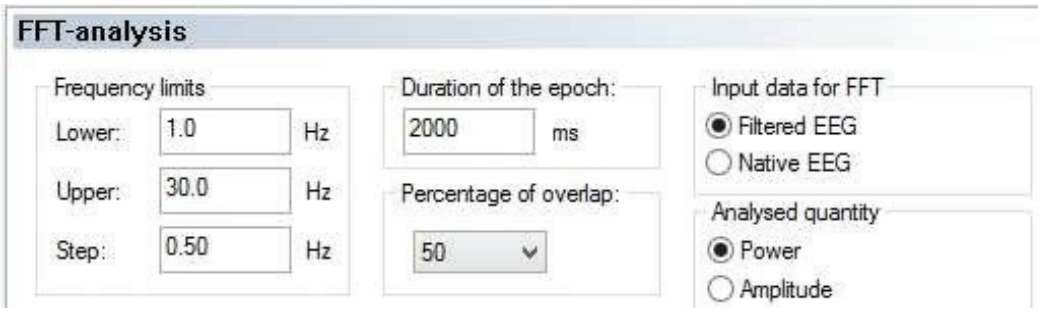

Fig. 3. FFT parameters

All experiments were performed in time frame from twelve to four p.m., in comfortable environment with the usage of provided by the supplier headphones.

The calculation of the sample size is performed with the usage of the following formula [11]:

$$
N=\frac{2 *\left(Z_{\alpha / 2}+Z_{\beta}\right)^{2}}{\left(\frac{d}{S d}\right)^{2}},
$$

where $N$-calculated sample siz;, $Z_{\alpha / 2}$ and $Z_{\beta}$-values of the normal distribution of probabilities $\alpha / 2$ and $\beta$ respectively; $d$ - clinically significant difference between group's mean values (effect size); $S d$ - standard deviation of obtained group data.

It is also less time consuming practice to estimate needed $N$ via analyzing Table 1 [11] for obtained $\mathrm{d} / \mathrm{SD}$ value.

\section{Table 1}

Example of a calculation table of sample sizes required to verify the statistical significance of the difference between the two mean values at the significance level of 0.05 and at the power of the criterion of 0.80 for different values of $\mathrm{d} / \mathrm{SD}$

\begin{tabular}{cccc}
\hline $\boldsymbol{d} / \boldsymbol{S} \boldsymbol{D}$ & $\begin{array}{c}\text { Estimated sample size for } \\
\text { one group }\end{array}$ & $\begin{array}{c}\text { Real sample size for } \\
\text { one group }(\boldsymbol{N})\end{array}$ & $\begin{array}{c}\text { Total sample size for } 2 \text { study groups (excluding } \\
\text { dropouts) }\end{array}$ \\
\hline 0.1 & 1568 & 1568 & 3136 \\
0.2 & 392 & 392 & 784 \\
0.3 & 174.2 & 174 & 348 \\
0.4 & 98 & 98 & 196 \\
0.5 & 62.72 & 63 & 126 \\
0.6 & 43.6 & 44 & 88 \\
0.7 & 32 & 32 & 64 \\
0.8 & 24.5 & 25 & 50 \\
0.9 & 19.4 & 20 & 40 \\
1 & 15.68 & 16 & 32 \\
1.1 & 13.0 & 13 & 26 \\
1.2 & 10.9 & 11 & 22 \\
1.3 & 9.3 & 10 & 20 \\
1.4 & 8 & 8 & 16 \\
1.5 & 7.0 & 7 & 14
\end{tabular}

Analysis of the results was conducted via Open Office Calc and Statistica program packages. For evaluation of the statistical data sampling method [14] and Student's t-criterion [15] were used. Detailed information about statistical methods, used in study, is presented in the next section.

\section{Results}

Out of 14 experiments 8 groups with results were formed and later were formed into other, comparative groups. Test results themselves consist of relative levels of $\delta$-rhythms of bioelectrical activity of the human brain during the test. 
Main division between test groups was their time placement relative to stress factor impact - group (7 experiments total), which took place before stress impact are marked as " $b$ ", ones (7 experiments total) after impact are marked with " $a$ ".

Another division consisted of result timing in the experiment itself - were distinguished two dividing points - results of the first minute (pre music exposure) are marked with number "1", results of the third minute (post music exposure) are marked with number " 3 ".

Last division was related to signal location in the human brain - mark "left" stands for the left brain hemisphere, mark "right" stands for the right brain hemisphere. Placements presented in "left" and "right" groups are shown in Table 2.

Table 2

Placement distribution

\begin{tabular}{cc}
\hline Hemisphere & Placement \\
\hline Left & Fp1, F3, F7, T3, T5, C3, P3, O1 \\
Right & Fp2, F4, F8, T4, T6, C4, P4, O2
\end{tabular}

For further reference it is important to name all new comparative groups - all of them consist of the comparison of relative $\delta$ rhythms levels in seven measurements put into results groups the first one compares result group, obtained before stress exposure during first minute of the recorded data from the left hemisphere to group, acquired after stress exposure during first minute of recorded data from the left hemisphere.

Next one compares result group, obtained before stress exposure during first minute of the recorded data from the right hemisphere to group, acquired after stress exposure during first minute of the recorded data from the right hemisphere.

Other one holds comparison of result group, obtained before stress exposure during third minute of the recorded data from the left hemisphere to group, acquired after stress exposure during third minute of the recorded data from the left hemisphere.

Next group includes comparison of group results, obtained before stress exposure during third minute of the recorded data from the right hemisphere to group, acquired after stress exposure during third minute of the recorded data from the right hemisphere.

Fifth group consists of the comparison of group results, obtained before stress exposure during first minute of the recorded data from the left hemisphere to group, acquired before stress exposure during of the third minute recorded data from the left hemisphere.

Sixth group consists of the comparison of group results, obtained before stress exposure during first minute of the recorded data from the right hemisphere to group, acquired before stress exposure during third minute of the recorded data from the right hemisphere.

Seventh group consists of the comparison of group results, obtained after stress exposure during first minute of the recorded data from the left hemisphere to group, acquired after stress exposure during third minute of the recorded data from the left hemisphere.

Eighth group consists of the comparison of group results, obtained after stress exposure during first minute of the recorded data from the right hemisphere to group, acquired after stress exposure during third minute of the recorded data from the right hemisphere.

Noteworthy is fact that for all comparative groups presence of statistically meaningful difference was obtained via implementation of Student's t-criterion, which practical usage is shown in studies $[16,17]$. That research had shown that the comparative groups 1 through 6 had it, while groups seven and eight did not.

After group forming mean values for each starting group were obtained and (as a part of a further statistical analysis) differences in comparison groups were estimated. All acquired results are presented in Table 3.

For the article it is necessary to set standard values of the level of significance condition (Type I error) (0.05) and power (0.80).

Then $Z_{a / 2}+Z_{b}=1.96+0.84=2.8$ and we can determine the value of the numerator for formula (1) equal to 15.68 [11].

Clinically significant difference between group's mean values is estimated in the next way all obtained differences in comparative groups are grouped and standard deviation for selected 
group is calculated. In the said groups result was obtained as a 5.56 percent. Then we take effect size as less than or equal to the calculated value. Relatively to the presented data, we assume effect size to be equal to $5 \%$ for all comparative groups.

Table 3

Group parameters

\begin{tabular}{|c|c|c|c|}
\hline \multirow{2}{*}{$\begin{array}{c}\text { Comparative group } \\
\text { number }\end{array}$} & \multirow{2}{*}{ Result group } & \multicolumn{2}{|c|}{ Test results } \\
\hline & & Mean value, $\%$ & Difference, $\%$ \\
\hline \multirow{2}{*}{1} & b. 1 left & 15.37 & \multirow{2}{*}{-7.11} \\
\hline & a. 1 left & 22.48 & \\
\hline \multirow{2}{*}{2} & b. 1 right & 14.43 & \multirow{2}{*}{-9.24} \\
\hline & a. 1 right & 23.67 & \\
\hline \multirow{2}{*}{3} & b. 3 left & 12.39 & \multirow{2}{*}{-10.4} \\
\hline & a. 3 left & 22.79 & \\
\hline \multirow{2}{*}{4} & b. 3 right & 12.21 & \multirow{2}{*}{-10.79} \\
\hline & a. 3 right & 23.011 & \\
\hline \multirow{2}{*}{5} & b. 1 left & 15.37 & \multirow{2}{*}{-2.97} \\
\hline & b. $3 \mathrm{left}$ & 12.39 & \\
\hline \multirow{2}{*}{6} & b. 1 right & 14.43 & \multirow{2}{*}{2.22} \\
\hline & b. 3 right & 12.21 & \\
\hline \multirow{2}{*}{7} & a. 1 left & 22.48 & \multirow{2}{*}{-0.32} \\
\hline & a. 3 left & 22.79 & \\
\hline \multirow{2}{*}{8} & a. 1 right & 23.67 & \multirow{2}{*}{0.66} \\
\hline & a. 3 right & 23.01 & \\
\hline
\end{tabular}

Standard deviation SD for comparative groups, and ratio $\frac{d}{S D}$ to are presented in Table 4. According to Table 1 we define $N$ equal to 7-14 for both groups - which corresponds with the results shown in the study. Also it is possible to note that there are possibilities for establishing minimal sample sizes even below this number.

Table 4

Method implementation results - comparative group parameters

\begin{tabular}{|c|c|c|}
\hline \multirow{2}{*}{ Comparative group number } & \multicolumn{2}{|c|}{ Test results } \\
\hline & Standard deviation & $d / S D$ ratio \\
\hline 1 & 3.03 & 1.65 \\
\hline 2 & 2.64 & 1.89 \\
\hline 3 & 2.2 & 2.28 \\
\hline 4 & 2.43 & 2.06 \\
\hline 5 & 2.36 & 2.12 \\
\hline 6 & 2.16 & 2.31 \\
\hline 7 & 2.9 & 1.72 \\
\hline 8 & 2.87 & 1.74 \\
\hline
\end{tabular}

\section{Discussion of research results}

Obtained results are twofold: first part shows that the presented experiment results are clinically correct and can show meaningful conclusion; second presents way for calculation of clinically significant difference between group's mean values for $\delta$-rhythms.

Although method was tried only for one type (of for obtained during experiments) of brainwave rhythms we can freely use it for other captured types.

Created method is tested only for relative values power of brainwave rhythms (estimated in percent) and should not be used (without previous testing) for the absolute values (estimated in $\mu \mathrm{V}$, $\mu \mathrm{V}^{2} / \mathrm{Hz}$ or $\mu \mathrm{W} / \mathrm{Hz}$ ), which are used, for example, in study [18]. 
It is also worth mentioning that required for obtaining the clinically significant difference between group's mean values part of the data have been calculated during estimation of t-criterion, so implementation of the proposed method is not neither time nor effort consuming.

Noteworthy is fact that in the sampling method was changed from convenient one [7] to the hybrid of stratified and quota methods [11, 14].

One of the newest studies [19] on one hand gives fundamental data on the ways of the sample data estimation, but, on the other one, does not provide way for estimation of the effect size.

Study limitations. The main restrictions on the use of the results, obtained in the study, are:

1) age of volunteers was in the limits from 18 to 22 years old;

2) all volunteers did not have a musical education, as this significantly affects the perception of musical fragments;

3 ) only first 3 minutes of total of 10 recorded were used in the analysis.

The plans for further researches are in double-checking the study results for $\alpha$-, $\beta$-, $\theta$ rhythms. Also improve Table 1 for even bigger d/SD values.

\section{Conclusions}

Obtained study results are twofold - at one side, method for selection of the minimal passable sample size for research of the relative $\delta$-rhythm levels change due to exposition to superposition of external factors (musical therapy and long-term growing study stress level) was produced and tested, on other side way of estimation of clinically significant difference between group means for $\delta$-rhythm was developed.

Relatively to the minimum passable sample size method estimation it is possible to name the following facts:

1. It is possible to use low-numbered (less than ten experiments in each - and seven in our case) test groups for the research of the relative $\delta$-rhythms levels change due to exposition to superposition of external factors (musical therapy and long-term growing study stress level). Although it is important to stress that moderation in sampling is recommended - it is better to have 3 groups of 7 test results then 8-13-2 [7] result group separation (though it is not always possible due to convenient sampling method [14] in presented study).

2. In contradistinction to the known methods $[8,10,11,19]$, method, presented in our study, is optimized for usage in studies, which utilize EEG as a medium for estimation of outside influence on CNS state.

3. Using the similarities between the nature of $\alpha-, \beta-, \theta$ - and $\delta$-rhythms (brainwave patterns) we can theorize that implementation of said method for different rhythms is possible.

4. Further research in terms of application of even less numerous test groups for specified problem are possible.

5. Method present way of manual correction of sample size estimation via careful estimation of clinically significant difference between test groups.

As for way of estimation of clinically significant difference between group means next facts are worth highlighting:

6 . In contrast to the presented sources $[11,19]$ not only direct application of clinically significant difference is shown, but way to calculate it for EEG based researches is shown.

7. The greater difference between mean values of components of the comparative group - the lower sample size is required for preserving clinically significant difference between test groups. methods.

8. Clinically significant difference can be adjusted via application of different rounding

\section{Conflict of interests}

The authors declare that they have no conflicts of interest.

\section{References}

[1] Rahman, M., Karwowski, W., Fafrowicz, M., Hancock, P. A. (2019). Neuroergonomics Applications of Electroencephalography in Physical Activities: A Systematic Review. Frontiers in Human Neuroscience, 13, 21. doi: http://doi.org/10.3389/ fnhum.2019.00182 
[2] Ernst, N., da Silva Fernando, L. (2005). Electroencephalography : Basic Principles, Clinical Applications, and Related Fields. Lippincott Williams \& Wilkins, 1309.

[3] Raglio, A., Attardo, L., Gontero, G., Rollino, S., Groppo, E., Granieri, E. (2015). Effects of music and music therapy on mood in neurological patients. World Journal of Psychiatry, 5 (1), 68-78. doi: http://doi.org/10.5498/wjp.v5.i1.68

[4] Derya Übeyli, E. (2009). Statistics over features: EEG signals analysis. Computers in Biology and Medicine, 39 (8), $733-741$. doi: http://doi.org/10.1016/j.compbiomed.2009.06.001

[5] Bullock, M., Jackson, G. D., Abbott, D. F. (2021). Artifact Reduction in Simultaneous EEG-fMRI: A Systematic Review of Methods and Contemporary Usage. Frontiers in Neurology, 12, 622719. doi: http://doi.org/10.3389/fneur.2021.622719

[6] Urigüen, J. A., García-Zapirain, B., Artieda, J., Iriarte, J., Valencia, M. (2017). Comparison of background EEG activity of different groups of patients with idiopathic epilepsy using Shannon spectral entropy and cluster-based permutation statistical testing. PLOS ONE, 12 (9), e0184044. doi: http://doi.org/10.1371/journal.pone.0184044

[7] Yoshinaga, H., Ohtsuka, Y., Tamai, K., Tamura, I., Ito, M., Ohmori, I., Oka, E. (2004). EEG in childhood absence epilepsy. Seizure, 13 (5), 296-302. doi: http://doi.org/10.1016/s1059-1311(03)00196-1

[8] Indira, V., Rasanthakumari, R., Sugumaran, V. (2012). Sample size determination for classification of eeg signals using power analysis in machine learning approach. International Journal of Advanced Research in Engineering \& Management, 3 (1), 1-9.

[9] Hwang, D., Schmitt, W., Stephanopoulos, G., Stephanopoulos, G. (2002). Determination of Minimum Sample Size and Discriminatory Expression Patterns. Bioinformatics, 18 (9), 1184-1193. doi: http://doi.org/10.1093/bioinformatics/18.9.1184

[10] Luh, W.-M., Olejnik, S., Guo, J.-H. (2008). Sample Size Determination for One-and Two-Sample Trimmed Mean Tests. The Journal of Experimental Education, 77 (2), 167-184. doi: http://doi.org/10.3200/jexe.77.2.167-184

[11] Tikhova, G. P. (2014). Planning clinical research. Question No. 1: How to calculate enough sample volume? Regionarnaia anesteziia i lechenie ostroi boli, 8 (3), 57-63.

[12] Liashko, D. (2020). Methods of music therapy and experimental study of bioelectrical activity of students' brains while listening to the musical composition of the audible frequency spectrum. ScienceRise, 6, 74-80. doi: http://doi.org/10.21303/ 2313-8416.2020.001561

[13] Sistema 10-20. Raspolozhenie elektrodov na golove (2021). СMI Brain Research. Available at: https://сті.to/ээг/системa-10-20/

[14] Taherdoost, H. (2016). Sampling Methods in Research Methodology; How to Choose a Sampling Technique for Research. International Journal of Academic Accounting, Finance \& Management Research., 5, 18-27. doi: http://doi.org/10.2139/ ssrn.3205035

[15] The Probable Error of a Mean (1908). Biometrika, 6 (1), 1-25. doi: http://doi.org/10.2307/2331554

[16] Pareniuk, D. V., Rudenka, K. L., Didkovskyi, V. S., Naida, S. A., Timen, H. E. (2018). The Study of Implementation of the Otoacoustic Emission for Registration of the Medicamentous Influence on the Auditory Channel of Guinea Pigs. Microsystems, Electronics and Acoustics, 23 (4), 74-81. doi: http://doi.org/10.20535/2523-4455.2018.23.4.134457

[17] Naida, S. A., Pareniuk, D. V., Timen, G. E., Rudenka, K. L. (2017). Otoacoustic emission as a diagnostic methodin experimental sensorineural hearing loss. Zhurnal vushnih, nosovih i gorlovih hvorob, 5, 13-20. Available at: http://www.lorlife.kiev. ua/2017/2017_5_13.pdf

[18] Tian, Y., Ma, L., Xu, W., Chen, S. (2020). The Influence of Listening to Music on Adults with Left-behind Experience Revealed by EEG-based Connectivity. Scientific Reports, 10 (1), 7575. doi: http://doi.org/10.1038/s41598-020-64381-x

[19] Serdar, C. C., Cihan, M., Yücel, D., Serdar, M. A. (2021). Sample size, power and effect size revisited: simplified and practical approaches in pre-clinical, clinical and laboratory studies. Biochemia Medica, 31 (1), 27-53. doi: http://doi.org/10.11613/ bm.2021.010502 